\title{
ENHANCEMENT OF CURRENT PEAK MULTIPLICITY RELATED TO CUPROUS OXIDE ELECTROREDUCTION AND TRANSIENT COPPER ACTIVATION IN ALKALINE SOLUTION
}

\author{
M.E. MARTINS and A.J. ARVIA \\ Instituto de Investigaciones Fisicoquímicas Teóricas y Aplicadas, INIFTA, Casilla de Correo 16, Sucursal 4, \\ 1900 La Plata (Argentina)
}

(Received 25th April 1983; in revised form 5th December 1983)

\section{ABSTRACT}

Anodic films formed on $\mathrm{Cu}$ electrodes immersed in $0.1 \mathrm{M} \mathrm{NaOH}$ in the $\mathrm{Cu} / \mathrm{Cu}(\mathrm{I})$ potential range were subjected to combined triangular potential sweeps and then immediately electroreduced to confirm the multiplicity of the species anodically formed and to investigate the roughening and sintering processes at the metal surface. These two processes are tentatively related to the increase in the cathodic current in the hydrogen evolution potential range, a fact which is apparently due to the electrode surface morphology attained after the potential perturbation programme was applied to the electrode, as deduced from SEM patterns.

\section{INTRODUCTION}

The potentiodynamic $E / I$ profile of $\mathrm{Cu}$ in alkaline solutions obtained between the potential region where hydrogen evolution takes place and the potential region related to electroformation of $\mathrm{Cu}_{2} \mathrm{O}$ changes appreciably with the characteristics of the potential perturbation [1-5]. Thus, when the $\mathrm{Cu}_{2} \mathrm{O}$ layer is electroformed by applying a potential sweep followed by a potential step to the electrode, various electroreduction current peaks related to the products formed during $\mathrm{Cu}_{2} \mathrm{O}$ electroformation are observed in the first sweep in the negative potential direction instead of the single peak resulting when the electrode is perturbed with a triangular potential sweep. The peak multiplicity extends in the potential range where supposedly most of the $\mathrm{Cu}(\mathrm{I})$ species is electroreduced and hydrogen evolution takes place.

This paper describes the current peak multiplicity involved in the electroreduction of $\mathrm{Cu}(\mathrm{I})$ species when the potentiodynamic ageing perturbation technique [6] is applied to the electrode. This multiplicity apparently appears simultaneously with a considerable increase in current in the hydrogen evolution potential range. The latter effect has also been recently reported for gold in acid solutions and for silver in alkaline solutions, when these electrodes are subjected to the same type of potential perturbation [7,8]. In the present case, an attempt is also made to correlate the 
electrochemical results with the morphology of the copper electrode surface as determined by SEM.

\section{EXPERIMENTAL}

A conventional three-compartment electrolysis Pyrex cell was used. Cu working electrodes were prepared from spectroscopic quality $\mathrm{Cu}$ wires $(0.4 \mathrm{~mm}$ diameter $)$. Electrode pretreatment consisted of first polishing with 400 mesh high purity alumina powder, then thorough rinsing with distilled water, and finally $15 \mathrm{~s}$ etching in $50 \% \mathrm{HNO}_{3}$ solution. This pretreatment gave reproducible results [2]. A large platinum sheet counter-electrode and a $\mathrm{Hg} / \mathrm{HgO} / 0.1 \mathrm{M} \mathrm{NaOH}$ reference electrode were used. All potentials are given against the normal hydrogen electrode. The electrolyte $(0.1 \mathrm{M} \mathrm{NaOH})$ was prepared from a.r. $\mathrm{NaOH}$ and triply distilled water. The solution was deaerated by bubbling purified nitrogen through the system before each run. Experiments were carried out at $30^{\circ} \mathrm{C}$.

To attain the stabilized $E / I$ profile, the electrode was initially perturbed with cyclic triangular potential sweeps (RTPS) at $0.2 \mathrm{~V} / \mathrm{s}$ between $E_{\mathrm{c}}=-1.29 \mathrm{~V}$ and $E_{\mathrm{a}}=-0.08 \mathrm{~V}$. Afterwards, the potentiodynamic ageing perturbation programme $[6,7]$ was applied to the electrode for a certain time, $\tau$ (number of cycles, $n$ ); the corresponding intermediate triangular potential sweeps (IRTPS) covered from $E_{\mathrm{c}}^{\prime}$ $\left(-0.49 \mathrm{~V}<E_{\mathrm{c}}^{\prime}<-0.36 \mathrm{~V}\right)$ to $E_{\mathrm{a}}\left(-0.19 \mathrm{~V}<E_{\mathrm{a}}<-0.08 \mathrm{~V}\right)$. The last IRTPS was followed by two complete TPS between $E_{\mathrm{c}}$ and $E_{\mathrm{a}}$. The corresponding $E /$ time diagram is depicted in each figure. The circuitry was the same as that used in previous work [4].

SEM photographs of the electrode surface were obtained from: (i) the recently polished electrode without electrochemical treatment; (ii) the electrode when the stabilized RTPS $E / I$ profile had been attained; (iii) the electrode after it was subjected to a pre-set number ( $n$ ) of IRTPS; and (iv) the electrode which immediately after perturbation indicated by (iii) was further subjected to RTPS to recover the stabilized $E / I$ profile.

\section{RESULTS}

The stabilized RTPS $E / I$ profile run at $0.2 \mathrm{~V} / \mathrm{s}$ covering from $E_{\mathrm{c}}=-1.29 \mathrm{~V}$ to $E_{\mathrm{a}}=-0.08 \mathrm{~V}$ exhibited a broad anodic current peak (API) located at ca. $-0.14 \mathrm{~V}$ and another broad cathodic current peak (CPI) at ca. $-0.46 \mathrm{~V}$ (Fig. 1a) [1-4]. This $E / I$ profile serves as a comparison to those resulting under the complex potential perturbation conditions.

After the electrodes had been subjected to potentiodynamic ageing perturbation between $E_{\mathrm{c}}^{\prime}$ and $E_{\mathrm{a}}$, the complete electroreduction $E / I$ profile from $E_{\mathrm{a}}$ to $E_{\mathrm{c}}$ resulting immediately afterwards (Fig. 1b, curve 1 ) showed a net increase in charge, a new cathodic current peak (CPT) whose peak potential was much more negative than that of CPI, and a considerable increase in current in the hydrogen evolution potential range. However, when the potential limits of the RTPS were reset at 


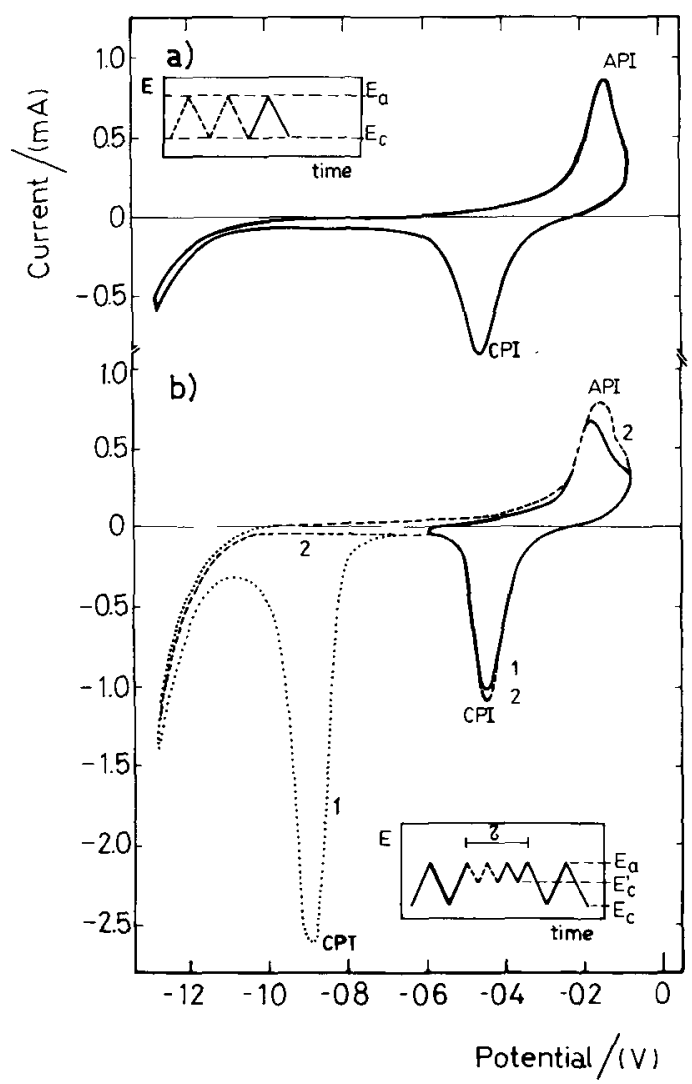

Fig. 1. Potentiodynamic $E / I$ profiles. $0.2 \mathrm{~V} / \mathrm{s}, 0.1 M \mathrm{NaOH}, 0.52 \mathrm{~cm}^{2}$ apparent electrode area, $25^{\circ} \mathrm{C}$. (a) Stabilized $E / I$ profile; (b) with IRTPS $E / I$ profile, $(\cdots \cdots)$ first TPS and (- --$)$ second TPS both run after the IRTPS. $E_{\mathrm{a}}=-0.08 \mathrm{~V}, E_{\mathrm{c}}=-1.29 \mathrm{~V}, E_{\mathrm{c}}^{\prime}=-0.59 \mathrm{~V}, \tau=12 \mathrm{~min}$.

$E_{\mathrm{a}}=-0.08 \mathrm{~V}$ and $E_{\mathrm{c}}=-1.29 \mathrm{~V}, \mathrm{CPT}$ disappeared and the initial stabilized $E / I$ profile was gradually reached (Fig. 1b, curve 2), although the overall charge remained greater than that of the initial stabilized $E / I$ profile, and the potential of API was shifted towards more positive potentials. The initial stabilized $E / I$ profile was only obtained after a prolonged RTPS between $E_{\mathrm{c}}$ and $E_{\mathrm{a}}$. The corresponding time depended on $E_{\mathrm{c}}^{\prime}, E_{\mathrm{a}}$ and $n$.

For pre-set $E_{\mathrm{c}}^{\prime}$ and $E_{\mathrm{a}}$ values, the heights of both API and CPI decreased as $n$ increased (Fig. 2). Furthermore, there was progressive passivation of the electrode as $n$ increased. The number of cycles required for complete passivation depended on $E_{\mathrm{c}}^{\prime}$ and $E_{\mathrm{a}}$. In this case, the potential of API remained constant and that of CPI moved towards more negative values.

On the other hand, when $E_{\mathrm{a}}$ was set at values more negative than $-0.13 \mathrm{~V}$, a reversible couple (couple I) in the -0.25 to $-0.30 \mathrm{~V}$ potential range was observed and it became more clearly defined as $n$ increased (Fig. 3). This redox couple, which is apparently the same as that described in previous investigations $[2,5]$, has been 


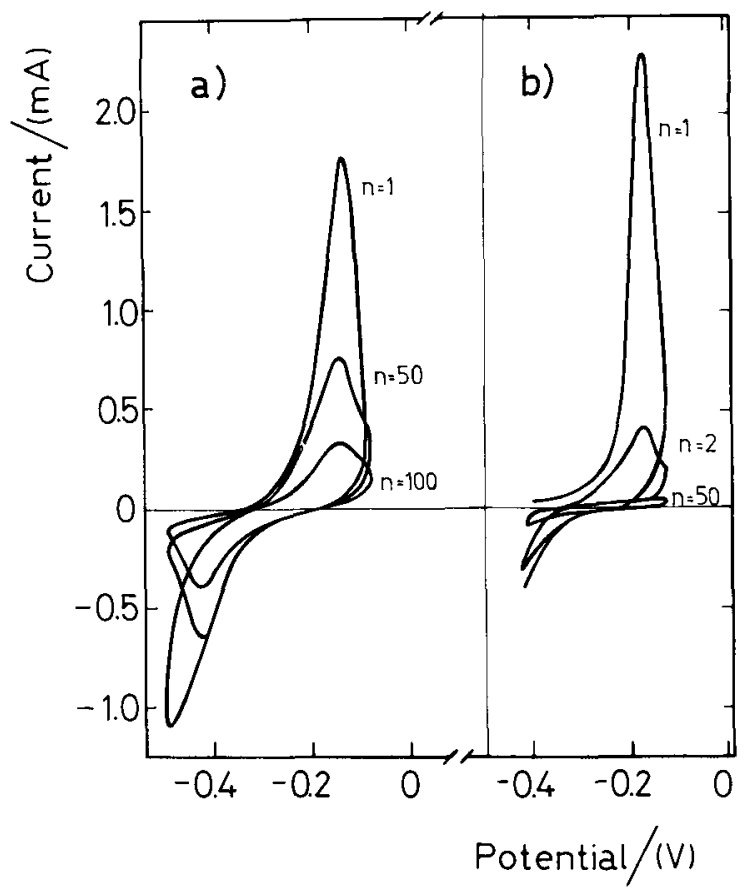

Fig. 2. IRTPS $E / I$ profiles. $0.2 \mathrm{~V} / \mathrm{s}, 0.1 M \mathrm{NaOH}, 0.85 \mathrm{~cm}^{2}$ apparent electrode area, $30^{\circ} \mathrm{C} . E_{\mathrm{a}}=-0.08$ V. (a) $E_{\mathrm{c}}^{\prime}=-0.50 \mathrm{~V}$; (b) $E_{\mathrm{c}}^{\prime}=-0.36 \mathrm{~V}$.

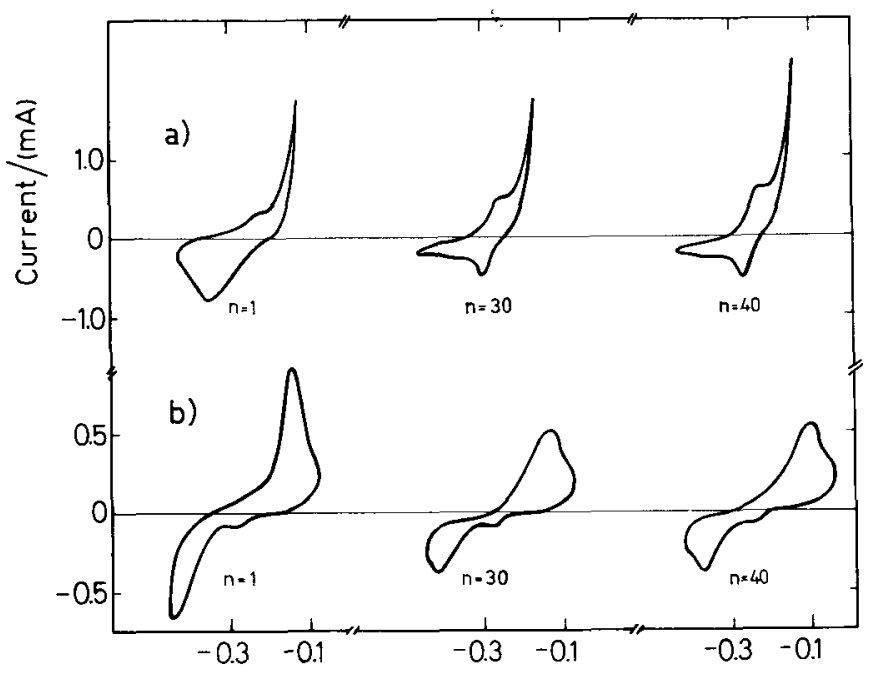

Fig. 3. IRTPS $E / I$ profiles. $0.2 \mathrm{~V} / \mathrm{s}, 0.1 M \mathrm{NaOH}, 0.79 \mathrm{~cm}^{2}$ apparent electrode area, $30^{\circ} \mathrm{C}$. (a) $E_{\mathrm{a}}=-0.16 \mathrm{~V}, E_{\mathrm{c}}^{\prime}=-0.46 \mathrm{~V} ;$ (b) $E_{\mathrm{a}}=-0.08 \mathrm{~V}, E_{\mathrm{c}}^{\prime}=-0.46 \mathrm{~V}$. 


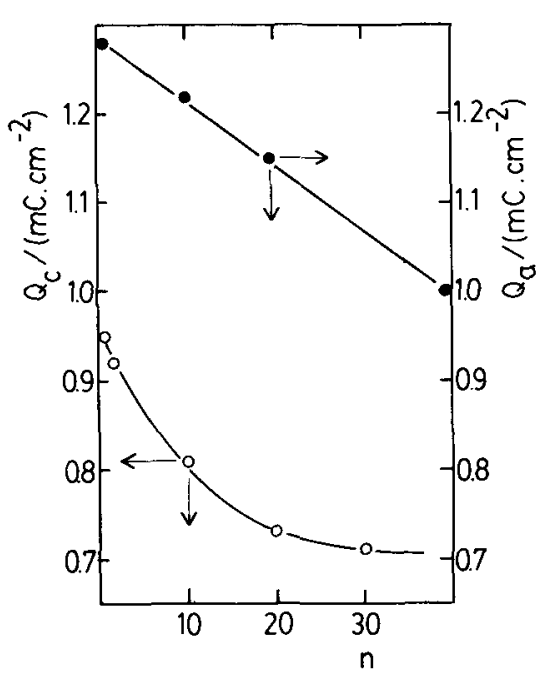

Fig. 4. Dependence of $Q_{\mathrm{c}}(\mathrm{O})$ and $Q_{\mathrm{a}}(\bullet)$ on $n .0 .1 M \mathrm{NaOH}, 0.39 \mathrm{~cm}^{2}$ apparent electrode area, $30^{\circ} \mathrm{C}$.

confirmed throughout runs made with vitreous carbon $/ \mathrm{Cu}(\mathrm{OH})_{2}$ electrodes immersed in alkaline solutions [4].

The charge of IRTPS decreased during cycling but the anodic charge $\left(Q_{\mathrm{a}}\right)$ was always greater than the cathodic charge $\left(Q_{c}\right)$ (Fig. 4). The complex nature of CPT can be visualized by an appropriate change in the potential perturbation parameters. For pre-set $E_{\mathrm{a}}, E_{\mathrm{c}}$ and $v$ values, the complete electroreduction profile run immediately after the IRTPS depended considerably on both $E_{c}^{\prime}$ and $n$, as clearly seen by comparing the profiles shown in Fig. 5. The plots of $E_{\mathrm{CPT}}$ vs. $n$ and $I_{\mathrm{CPT}}$ vs. $n$ (Fig. 6) indicate that the height of CPT increased and its peak potential gradually shifted towards more negative potentials as $n$ increased.

On the other hand, at constant $E_{\mathrm{a}}$ and $n$, the symmetry, the charge and the peak potential of CPT changed in a complex way with $E_{c}^{\prime}$. Thus, when $E_{c}^{\prime}$ was more negative than $-0.50 \mathrm{~V}$ only one peak was observed, but as $E_{\mathrm{c}}^{\prime}$ became more positive than $-0.41 \mathrm{~V}$ the peak multiplicity in the electroreduction $E / I$ profile was recorded. Otherwise, a further increase in $E_{c}^{\prime}$ beyond $-0.36 \mathrm{~V}$ again produced an electroreduction profile with only a single peak at ca. $-0.7 \mathrm{~V}$ (Fig. 5). The charge of CPT, estimated from the charge difference $\sum_{0}^{n} Q_{\mathrm{a}}-\sum_{0}^{n} Q_{\mathrm{c}}$ increased linearly with $n(0<n<$ 40) (Fig. 7). Likewise, for a constant $n$ as $E_{\mathrm{c}}^{\prime}$ became more positive, first a charge increase in CPT was noticed but the reverse occurred when $E_{\mathrm{c}}^{\prime}$ extended beyond $-0.36 \mathrm{~V}$. The most remarkable splitting of the electroreduction $E / I$ profile and charge difference were accomplished for $E_{\mathrm{a}}=-0.16 \mathrm{~V}, E_{\mathrm{c}}^{\prime}=-0.41 \mathrm{~V}$ and $n=40$. Otherwise, for $E_{\mathrm{c}}^{\prime}=-0.37 \mathrm{~V}$, CPT exhibited a shoulder at the negative potential side and for $E_{\mathrm{c}}^{\prime}=-0.46 \mathrm{~V}$, the latter turned into a new cathodic peak (Fig. 8). Therefore, CPT splits into various peaks whose peak potentials were at ca. $-0.78 \mathrm{~V}$ (CPI') and $-0.88 \mathrm{~V}$ (CPII) (Fig. 8). When $E_{\mathrm{c}}^{\prime}$ exceeded $-0.41 \mathrm{~V}$, the height of CPII increased while that of $\mathrm{CPI}^{\prime}$ decreased. 


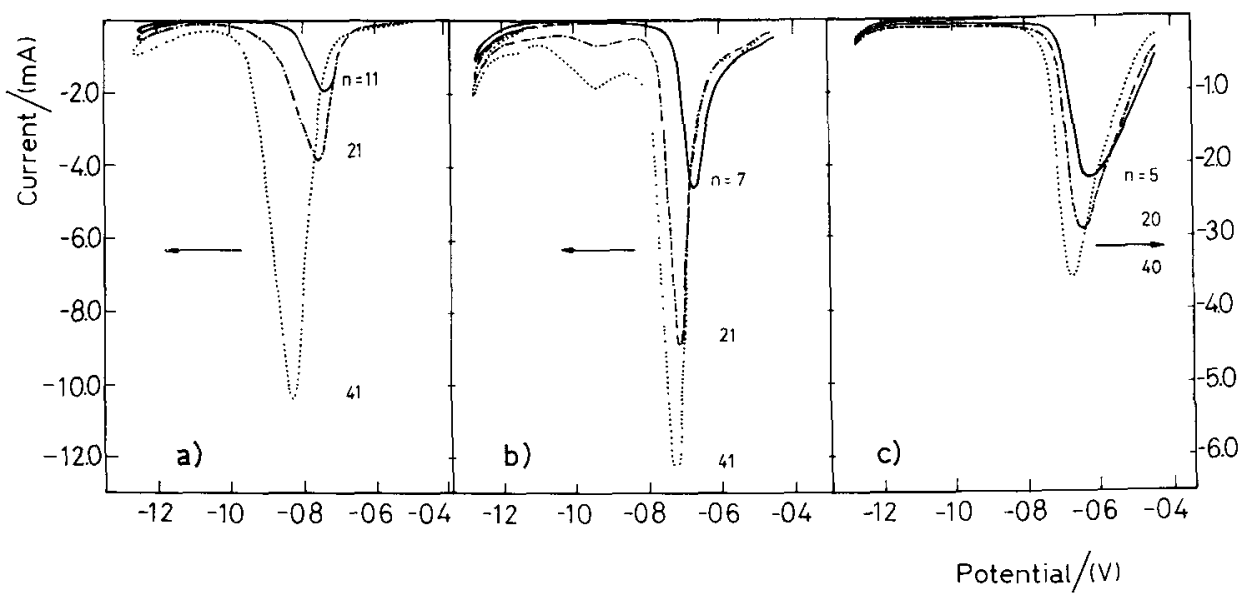

Fig. 5. Influence of $\tau$ on the electroreduction $E / I$ profile. $E_{\mathrm{a}}=-0.08 \mathrm{~V} .0 .1 \mathrm{M} \mathrm{NaOH}$. (a) $E_{\mathrm{c}}^{\prime}=-0.50 \mathrm{~V}$, $0.39 \mathrm{~cm}^{2}$ apparent electrode area, $(-) n=11,(\cdot \cdots) n=21,(\cdots \cdots) n=41 ;$ (b) $E_{\mathrm{c}}^{\prime}=-0.41 \mathrm{~V}$, $0.86 \mathrm{~cm}^{2}$ apparent electrode area, $(\longrightarrow) n=7,(\cdot-\cdot) n=21,(\cdots \cdots) n=41 ;$ (c) $E_{\mathrm{c}}^{\prime}=-0.36 \mathrm{~V}$, $0.86 \mathrm{~cm}^{2}$ apparent electrode area, $(\longrightarrow) n=5,(\cdot \cdots \cdot \cdot) n=20,(\cdots \cdots) n=40,30^{\circ} \mathrm{C}$.
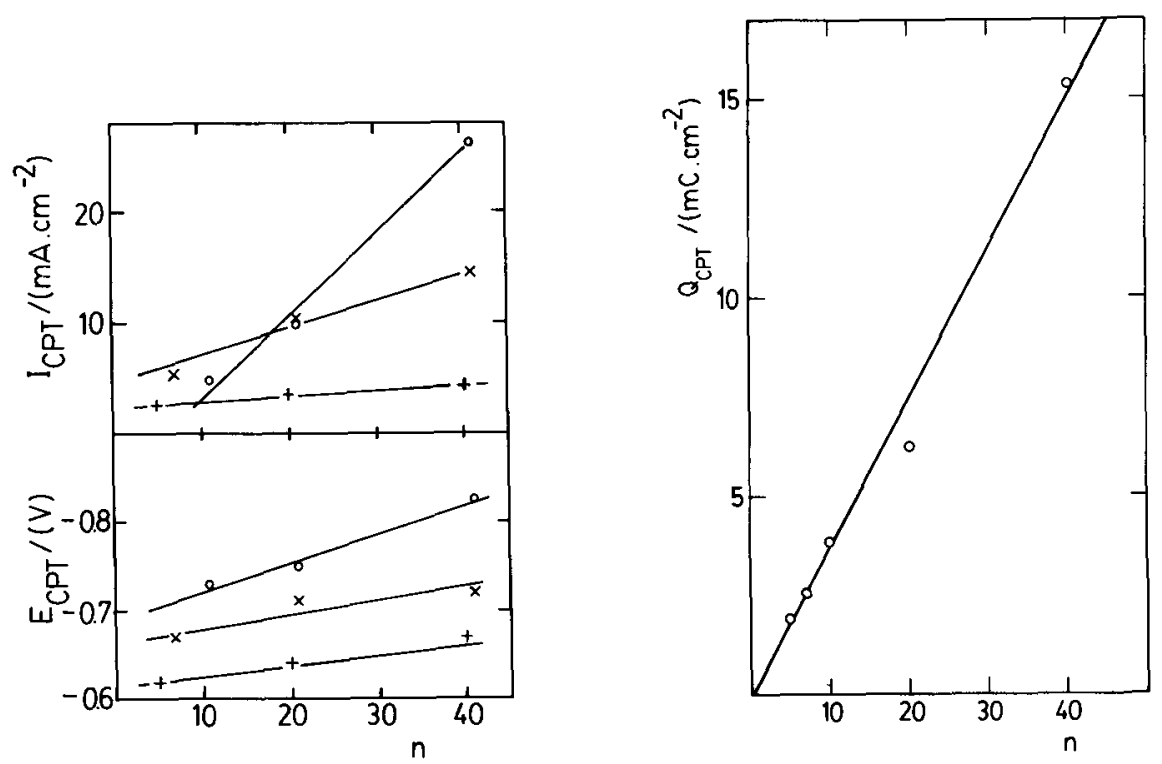

Fig. 6. Influence of $n$ of $E_{\mathrm{CPT}}$ and $I_{\mathrm{CPT}} .0 .1 M \mathrm{NaOH} . E_{\mathrm{a}}=-0.08 \mathrm{~V} ; E_{\mathrm{c}}^{\prime}=-0.50 \mathrm{~V}(0), 0.39 \mathrm{~cm}^{2}$ apparent electrode area; $E_{\mathrm{c}}^{\prime}=-0.41 \mathrm{~V}(\times), 0.86 \mathrm{~cm}^{2}$ apparent electrode area; and $E_{\mathrm{c}}^{\prime}=-0.36 \mathrm{~V}(+)$, $0.86 \mathrm{~cm}^{2}$ apparent electrode area, $30^{\circ} \mathrm{C}$.

Fig. 7. Influence of $n$ on the CPT. $E_{\mathrm{c}}^{\prime}=-0.66 \mathrm{~V}: E_{\mathrm{a}}=-0.08 \mathrm{~V} .0 .1 M \mathrm{NaOH}, 0.39 \mathrm{~cm}^{2}$ apparent electrode area, $30^{\circ} \mathrm{C}$. 

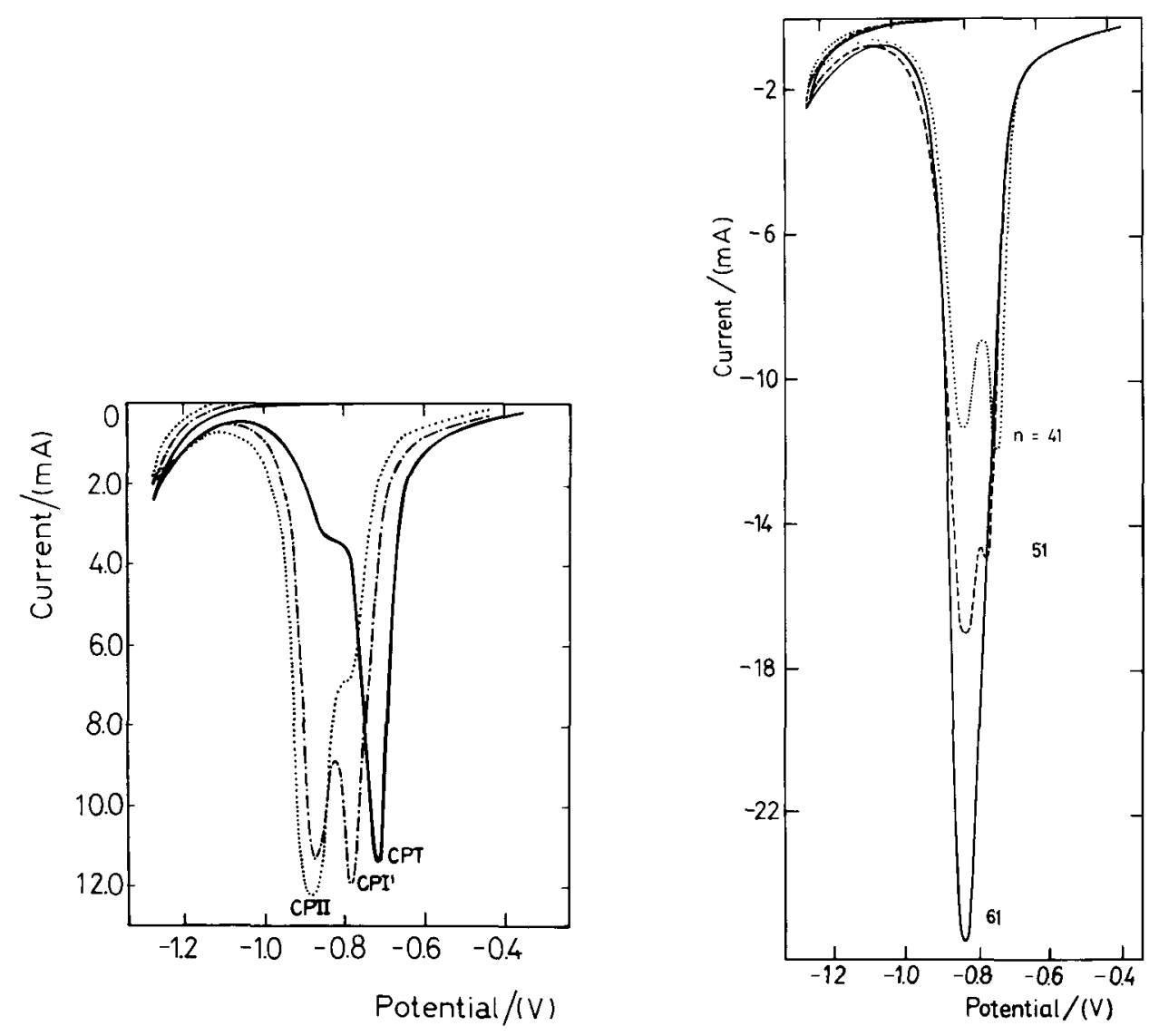

Fig. 8. Influence of $E_{\mathrm{c}}^{\prime}$ on the electroreduction profiles, $n=41 ; E_{\mathrm{a}}=-0.16 \mathrm{~V}, 0.1 M \mathrm{NaOH}, 0.79 \mathrm{~cm}^{2}$ apparent electrode area, $30^{\circ} \mathrm{C}$. (— $\left.) E_{\mathrm{c}}^{\prime}=-0.37 \mathrm{~V} ;(\cdots)\right) E_{\mathrm{c}}^{\prime}=-0.46 \mathrm{~V} ;(\cdot-\cdot-\cdot) E_{\mathrm{c}}^{\prime}=-0.62 \mathrm{~V}$.

Fig. 9. Influence of $n$ on the electroreduction $E / I$ profiles. $E_{\mathrm{a}}=-0.16 \mathrm{~V} ; E_{\mathrm{c}}^{\prime}=-0.62 \mathrm{~V} .0 .1 \mathrm{M} \mathrm{NaOH}$, $0.79 \mathrm{~cm}^{2}$ apparent electrode area, $30^{\circ} \mathrm{C} .(\cdots \cdots) n=41,(-\ldots-) n=51,(-) n=61$.

When $E_{\mathrm{c}}^{\prime}$ was in the $-0.41 \mathrm{~V}<E_{\mathrm{c}}^{\prime}<-0.50 \mathrm{~V}$ range, after the IRTPS a progressive increase in the current in the hydrogen evolution potential range was also noticed. This effect was no longer observed when $E_{\mathrm{c}}^{\prime}>-0.36 \mathrm{~V}$.

Similar changes in the electroreduction profile were accomplished by increasing $n$, that is the duration of the IRTPS. Thus, the contribution of the shoulder in CPT increased with $\tau$, resulting in a new current peak at $-0.84 \mathrm{~V}$. The height of the latter gradually increased with $n$, while that of CPI decreased and finally disappeared (Figs. 8 and 9). This splitting appeared only for $-0.39 \mathrm{~V}>E_{\mathrm{c}}^{\prime}>-0.44\left(E_{\mathrm{a}}=-0.16\right.$ V).

The SEM pictures (Fig. 10) show an increase in the roughness of the electrode surface caused by the IRTPS. This effect is probably associated with the decrease in the average size of crystallites forming the anodic film. 

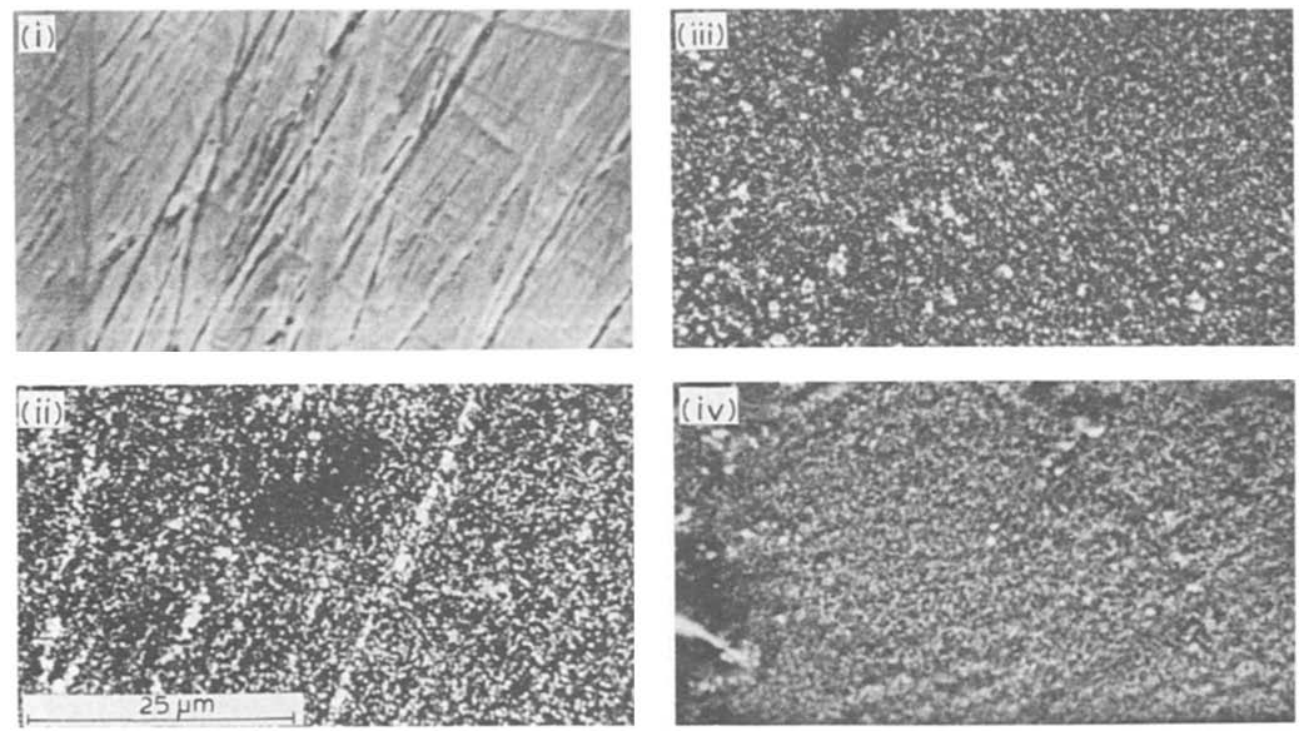

Fig. 10. SEM photographs obtained from (i) a recently polished electrode without electrochemical treatment; (ii) an electrode after the stabilized RTPS $E / I$ profile had been attained: (iii) an electrode after $n=1260$ IRTPS cycles $\left(1 \mathrm{~h} 45 \mathrm{~min}\right.$ ) at $E_{\mathrm{a}}=-0.2 \mathrm{~V}, E_{\mathrm{c}}^{\prime}=-0.7 \mathrm{~V}, v=0.2 \mathrm{~V} / \mathrm{s}, n=1260$ cycles; (iv) an electrode which immediately after the perturbation indicated in (iii) was further subjected to RTPS to recover the stabilized RTPS $E / I$ profile.

\section{DISCUSSION}

When copper electrodes are anodized in the potential range where $\mathrm{Cu}(\mathrm{I})$ species are formed, the potentiodynamic electroreduction response depends on the potential perturbation programme. Thus, it is possible to apply to the electrode: (i) a simple RTPS [1]; (ii) a positive potential step preceding the positive potential sweep [3]; (iii) a potential step included during the positive sweep to complete the formation of $\mathrm{Cu}_{2} \mathrm{O}$ under constant potential conditions [3]; and (iv) a potentiodynamic ageing potential programme [6]. In all these cases, except (i), the electroreduction potentiodynamic $E / I$ profile exhibits a multiplicity of peaks which depends on the proper characteristics of the perturbation programme.

The application of potentiodynamic ageing perturbation programmes to $\mathrm{Cu}$ electrodes in alkaline solutions in the potential range corresponding to electroformation of $\mathrm{Cu}(\mathrm{I})$ species produces a multiplicity of peaks in the electroreduction $E / I$ profile when the sweep is extended from the $\mathrm{Cu}_{2} \mathrm{O}$ electroformation potential range to that of hydrogen evolution. These changes in electroreduction profile are comparable to those already described under other potential perturbation conditions $[2,3]$.

The strong dependence of the electrochemical response of $\mathrm{Cu}$ electrodes on the characteristics of the potential perturbation programme explains the difficulty of a 
mechanistic interpretation of the kinetics of the electrode processes as well as the number of reaction models which were put forward to account for the data obtained in the $\mathrm{Cu} / \mathrm{Cu}(\mathrm{I})$ potential range [3]. Previous studies concluded from the multiple peaks found in the electroreduction potentiodynamic $E / I$ profile [2] that soluble $\mathrm{Cu}(\mathrm{I})$ and $\mathrm{Cu}(\mathrm{II})$ species are produced during electroformation of the complex $\mathrm{Cu}(\mathrm{OH})_{\mathrm{ad}}$ and $\mathrm{Cu}_{2} \mathrm{O}$ layers.

Basically, data derived from the combined TPS used in this work can be analysed either in terms of the $E / I$ profile variation during each successive IRTPS or in terms of the overall electroreduction $E / I$ profile resulting immediately after the IRTPS perturbation was applied. The main difference between these analyses lies in the anodic charge taking part during the corresponding perturbation, which in the former is a film of the order of one monolayer thickness, while in the latter it corresponds to a relatively thin multilayer. In this case, the maximum in the multiplicity and the distribution of the cathodic charge among the various peaks are associated with relatively restricted ranges of $n, E_{\mathrm{c}}^{\prime}$ and $E_{\mathrm{a}}$ values, namely when the charge of either $\mathrm{Cu}(\mathrm{OH})_{\mathrm{ad}}$ or $\mathrm{Cu}_{2} \mathrm{O}$ involved in each IRTPS corresponds to the average thickness of a monolayer or a few monolayers. On the other hand, as the thickness of the anodic layer increases, as measured through the overall electroreduction charge. a gradual increase in the contribution of CPT is recorded. Then the potential of CPT and the multiplicity distribution of the electroreduction profile depend on the amount of oxide electroformed during the IRTPS.

The roughness of the electrode increases to reach a maximum value, which depends on the IRTPS characteristics and on $n$. But the electrode roughness is apparently smeared out by RTPS covering the potential range between that of the $\mathrm{Cu}_{2} \mathrm{O}$ electroformation and the potential range of the hydrogen evolution (Fig. 1). In this case, it appears that surface roughness and sintering are competitive processes occurring during the $\mathrm{Cu}(\mathrm{I})+e^{-}=\mathrm{Cu}$ reaction. This conclusion correlates with the sequence of SEM photographs of the surface (Fig. 10), which show randomly distributed spheres on the surface, the sphere diameter being ca. $50 \mathrm{~nm}$. The spheres change into a continuous rough surface when the IRTPS is followed by a RTPS, as already described. Processes such as $\mathrm{Cu}$ surface reconstruction and roughening, which are apparently emphasized through the application of IRTPS, should be related to re-accommodation of $\mathrm{Cu}$ and $\mathrm{O}$ atoms and to electroadsorption/ electrodesorption of $\mathrm{OH}^{-}$ions during the potential cycling.

If one admits that the IRTPS increases the roughness of the electrode, the initial stages in the formation of the anodic layer can be explained provided that different active sites on the electrode surface, such as those in planes, at the borders of steps, in the bottom of holes, etc., participate in the reaction. This should imply an instantaneous non-equilibrium situation of different $\mathrm{O}$-containing species as well as $\mathrm{Cu}$ itself, during both the electrooxidation and the electroreduction processes. During the electroreduction process the IRTPS promotes a large surface concentration of non-equilibrium $\left(\mathrm{Cu}^{*}\right)$ species, which in the time scale of the potential perturbation are unable to attain thermal equilibrium conditions [9]. The $\mathrm{Cu}^{*}$ species exhibits, in principle, a reactivity greater than that of the equilibrated $\mathrm{Cu}$ 
species. This species can, in principle, be considered responsible for the apparent increase in the $\mathrm{H}_{2}$ evolution current on the freshly formed $\mathrm{Cu}$ surface. This effect, however, can be related either to the increase in roughness or to the proper characteristics of the fresh $\mathrm{Cu}^{*}$ surface formed from electroreduction of the $\mathrm{O}$-containing $\mathrm{Cu}$ species.

On the other hand, the increase in cathodic current takes place simultaneously with the appearance of the reversible couple (couple I) preceding the main anodic current peak. This couple is related to the reaction [4]:

$\mathrm{Cu}^{*}+\mathrm{OH}^{-} \rightleftarrows \mathrm{Cu}^{*}(\mathrm{OH})_{\mathrm{ad}}+e^{-}$

where $\mathrm{Cu}^{*}$ denotes a $\mathrm{Cu}$ atom under non-equilibrium conditions at the surface. In this case, the electrochemical response of the $\mathrm{Cu}$ surface after the IRTPS is similar to that observed for thin copper layer electrodes [4]. Moreover, reaction (1) may contribute to $\mathrm{Cu}^{*}$ deactivation, as earlier suggested, through a reaction such as

$\mathrm{Cu} *(\mathrm{OH})_{\mathrm{ad}} \rightleftarrows \mathrm{Cu}(\mathrm{OH})_{\mathrm{ad}}$

Furthermore, the deactivation of $\mathrm{Cu}^{*}$ should also occur through re-accommodation in the lattice:

$\mathrm{Cu}^{*} \rightleftarrows \mathrm{Cu}$ (lattice)

This reaction is to a great extent associated with the sintering effect [10-12]. The rate of reaction (3) should depend on the concentration of the $\mathrm{Cu}^{*}$ species, although the specific rate constant regarded as similar to that deduced from the rate of thermal equilibration is apparently low.

The transient formation of $\mathrm{Cu}^{*}$ explains the increase in current in the hydrogen evolution potential range which is beyond that expected from the roughness effect. This apparent activation of the hydrogen evolution reaction can be expressed by the following reaction:

$\mathrm{Cu}^{*}+\mathrm{H}_{2} \mathrm{O}+e^{-} \rightleftarrows \mathrm{Cu}^{*}(\mathrm{OH})_{\mathrm{ad}}^{-}+\frac{1}{2} \mathrm{H}_{2}$

This type of activation for the hydrogen evolution reaction has already been observed for $\mathrm{Au}$ in acid electrolytes [7] and for $\mathrm{Ag}$ in alkaline solutions [8]. In principle, reaction (4) should be facilitated by the greater interaction between $\mathrm{Cu}^{*}$ and $\mathrm{H}_{2} \mathrm{O}$ within a potential range which probably lies close to the potential of zero charge of $\mathrm{Cu}$ in the electrolyte solution.

Finally, it is worthwhile mentioning that both the enhancement multiplicity of the electroreduction profile and the cathodic current in the hydrogen evolution potential range as seen in gold, silver and copper through the application of the combined triangular potential sweep perturbation appears, in principle, to be related to the formation of small spherical particles of fairly constant diameter packed together on the electrode. The sphere diameters are, in principle, in the order of those found for gold, silver and copper electrodes to produce an efficient enhancement of the corresponding Raman spectra [13]. This encourages a study to establish a quantitative correlation between the corresponding electrochemical and optical results. 


\section{ACKNOWLEDGEMENTS}

INIFTA is sponsored by the Consejo Nacional de Investigaciones Cientificas y Técnicas, the Universidad Nacional de la Plata and the Comisión de Investigaciones Científicas (Provincia de Buenos Aires).

\section{REFERENCES}

1 A.M. Castro Luna de Medina. S.L. Marchiano and A.J. Arvia, J. Appl. Electrochem., 8 (1978) 121.

2 S.L. Marchiano, C.I. Elsner and A.J. Arvia, J. Appl. Electrochem., 10 (1980) 365.

3 M.R. Gennero de Chialvo, S.L. Marchiano and A.J. Arvía, J. Appl. Electrochem., in press.

4 M.R. Gennero de Chialvo, S.L. Marchiano and A.J. Arvía, in preparation.

5 J.M.M. Droog, C.A. Alderstein, P.T. Alderstein and G.A. Bootsma, J. Electroanal. Chem., 111 (1970) 61 .

6 M.E. Folquer, J.O. Zerbino, N.R. de Tacconi and A.J. Arvía, J. Electrochem. Soc., 126 (1979) 592.

7 R. Córdova O., M.E. Martins and A.J. Arvía, J. Electrochem. Soc., 127 (1980) 2628.

8 G.I. Lacconi and A.S. Gioda, Resúmenes extendidos del XVI Congreso Argentino de Química, Córdoba. 1982.

9 J.O'M. Bockris and E. Buck, Structure and Properties of Metal Surfaces, Maruzen, Tokyo, 1973.

10 P. Stonehart and P.A. Zucks, Electrochim. Acta, 17 (1972) 2333.

11 A.C.C. Tseung and S.C. Dhara, Electrochim. Acta, 20 (1975) 681.

12 A.E. Bolzán, M.E. Martins and A.J. Arvia, J. Electroanal. Chem., 157 (1983) 339.

13 C.C. Busby and J.A. Creighton, J. Electroanal. Chem., 140 (1982) 379. 